\title{
Penerapan Metode Profile Matching Pada Proses Seleksi Rekrutmen Pegawai Berdasarkan Faktor Kompetensi Spencer
}

\author{
Rani Purbaningtyas \\ Prodi Teknik Informatika \\ Universitas Bhayangkara Surabaya \\ Surabaya, Indonesia \\ email : raniubhara@gmail.com
}

\begin{abstract}
One of the keys to the company's success is how to place the right people in the right positions. For this reason, the recruitment selection process plays a significant role. This study applies the Profile Matching method to the employee recruitment selection process for the marketing director position. The prerequisites for occupying the position of marketing director are based on 20 Spencer competency factors divided into 6 competency groups with varying weights. The Spencer competency groups used along with the weight variations are Achievement and Action (AA) - 30\%, Helping and Human Service (HHS) - 5\%, Impact and Influence (IMIN) - 10\%, Managerial (MNG) - 30\%, Cognitive (COG) - 15\% and Personal Effectiveness (PE) $-10 \%$. The results showed that the employee on behalf of Candidate 8 was the strongest candidate for the Marketing Director position with a score based on the Spencer competency factor of 4.46 points.
\end{abstract}

Keywords-recruitment selection process; profile matching; Spencer competency

Abstrak - Salah satu kunci keberhasilan perusahaan adalah bagaimana menempatkan orang yang tepat pada jabatan yang sesuai. Untuk itu, proses seleksi rekrutmen memegang peranan yang sangat penting. Penelitian ini menerapkan metode Profil Matching pada proses seleksi rekrutmen pegawai untuk menduduki jabatan marketing director. Dimana prasyarat untuk menduduki jabatan marketing director didasarkan pada 20 faktor kompetensi Spencer yang terbagi menjadi 6 kelompok kompetensi dengan variasi bobot. Kelompok kompetensi Spencer yang digunakan beserta variasi bobot yaitu Achievement and Action (AA) $30 \%$, Helping and Human Service (HHS) - 5\%, Impact and Influence (IMIN) - 10\%, Managerial (MNG) - 30\%, Cognitive (COG) - 15\% dan Personal Effectiveness (PE) - 10\%. Hasil penelitian menunjukkan pegawai dengan kode Kandidat 8 merupakan kandidat terkuat untuk menduduki posisi Marketing Director dengan perolehan nilai berdasarkan faktor kompetensi Spencer sebesar 4,46 poin.

Keywords-proses seleksi rekrutmen, metode Profil Matching, faktor kompetensi Spencer

\section{PENDAHULUAN}

Sumber daya yang dimiliki oleh suatu perusahaan dikategorikan menjadi 6 jenis yaitu manusia (man), uang (money), mesin (technology), material (asset), metode (method) dan pasar (market) [1]. Sumber daya manusia merupakan salah satu faktor perusahaan yang memegang peranan penting untuk perkembangan perusahaan [2]. Sehingga bagaimana menempatkan seseorang pada suatu jabatan yang tepat menjadi kunci keberhasilan dari keberlangsung perusahaan dalam menjalankan usahanya [3]

Untuk memenuhi kondisi tersebut, hal pertama yang harus dilaksanakan terlebih dahulu ada menentukan prasyarat apa saja yang harus dipenuhi seseorang untuk menduduki jabatan tertentu di perusahaan [4]. Proses ini disebut dengan analisa jabatan. Melalui proses analisa jabatan akan diperoleh deskripsi lengkap mengenai jenis pekerjaan atau jabatan yang dimaksud meliputi kewajiban, tanggung jawab, kondisi kerja, dan peralatan kerja yang dibutuhkan [5]. Analisa jabatan juga dapat menentukan kompetensi apa saja yang harus dimiliki oleh seseorang untuk menjalankan atau menduduki jabatan tersebut [6].

Kompetensi menurut Spencer\&Spencer didefinisikan sebagai karateristik dasar perilaku individu yang berhubungan dengan kriteria acuan efektif atau kinerja unggul dalam pekerjaan. Kompetensi sebagai karakteristik yang mendasari seseorang berkaitan dengan efektivitas kinerja individu dalam pekerjaanya. Kompetensi sebagai karakteristik dasar individu yang memiliki hubungan kausal atau sebab akibat dengan kriteria yang dijadikan acuan, efektitif atau berkinerja prima atau superior ditempat kerja atau pada situasi tertentu [7]

Luaran dari analisa jabatan akan berjalan optimal jika diiringi dengan proses seleksi yang tepat di tahap rekrutmen pegawai. Banyak varian metode yang diterapkan pada proses seleksi rekrutmen pegawai. Seperti metode KNN yang diterapkan pada proses e-recruitment dosen Universitas Muhammadiyah Riau [8], seleksi penerimaan karyawan di PT Raja Kapal menggunakan SAW [9], penerapan metode TOPSIS untuk seleksi penerimaan karyawan baru [10], penerapan AHP untuk seleksi penerimaan asisten laboratorium [11] hingga kombinasi penerapan metode TOPSI-AHP pada seleksi rekrutmen pegawai baru [12]. Selain itu juga ada penerapan metode profile matching pada seleksi rekrutmen pegawai untuk menentukan perubahan status pegawai dari kontrak menjadi tetap [13]. Dimana pada setiap penerapan metode rekrutmen diatas disesuaikan dengan persyaratan dari masing-masing jabatan yang akan diisi sesuai dengan karakteristik masingmasing perusahaan tersebut [14]

Penelitian ini menerapkan metode profile matching pada proses seleksi rerutmen pegawai yang dikombinasikan dengan faktor kompetensi Spencer sebagai faktor prasyarat 
jabatan. Kompetensi Spencer dipilih karena faktor kompetensi ini merupakan salah satu indikator umum yang banyak digunakan di perusahaan-perusahaan besar maupun instansi pemerintahan [15][16] Sedangkan metode profile matching dirasa tepat karena metode ini menerapkan mekanisme pengambilan keputusan dengan mengasumsikan bahwa terdapat tingkat variabel predictor ideal yang harus dimiliki oleh subyek yang diteliti, bukannya tingkat minimal yang harus dipenuhi [17]. Dengan menerapkan metode profile matching pada proses seleksi rekrutmen pegawai berdasarkan faktor kompetensi Spencer diharapkan dapat membantu divisi sumber daya manusia untuk menentukan individu yang tepat dalam menduduki jabatan tertentu berdasarkan faktor kompetensi yang disyaratkan.

\section{METODE}

Tahapan proses penelitian dilaksanakan setelah analisa jabatan selesai. Tahapan dari analisa jabatan sendiri terdiri dari :

1. menentukan job description

2. menentukan spesifikasi jabatan

3. menentukan klasifikasi jabatan

4. mendeskripsikan job requirement

Untuk setiap posisi jabatan yang tersedia nantinya akan memiliki deskripsi job requirement yang berbeda-beda. Deskripsi dari job requirement untuk tiap posisi jabatan inilah yang akan ditetapkan menggunakan faktor kompetensi Spencer. Ada 20 faktor kompetensi Spencer yang harus dipenuhi untuk setiap jabatan yang tersedia. Faktor kompetensi Spencer terbagi menjadi 6 kelompok yaitu achievement and action (AA), helping and human service (HHS), the impact and influence (IMIN), managerial (MNG), cognitive (COG), dan personal effectiveness (PE).

Dimana setiap kelompok memiliki bobot atau tingkat kepentingan yang berbeda di tiap prasyarat jabatan. Kelompok achievement and action terdiri dari achievement orientation (ACH), concern for order (CO), initiative (INT), information seeking (INFO). Kelompok helping and human service terdiri dari interpersonal understanding (IU) dan customer service orientation (CSO). Kelompok the impact and influence terdiri dari impact and influence (IMP), organizational awareness (OA), dan relationship building (RB). Kelompok managerial terdiri dari developing others (DEV), directiveness (DIR), teamwork (TW), dan team leadership (TL). Kelompok cognitive terdiri dari analytical thinking (AT), conceptual thinking (CT), dan expertise (EXP). Sedangkan kelompok personal effectiveness terdiri dari self-control (SCT), self-confidence (SCF), flexibility (FLX), dan organizational commitment (OC).

Selanjutnya dari setiap kandidat pegawai yang melamar, akan dihitung tingkat kesesuaian antara kompetensi yang dimiliki kandidat pegawai tersebut terhadap syarat kompetensi jabatan yang diprasyaratkan. Perhitungan tingkat kesesuaian kompetensi menggunakan metode profile matching. Dari setiap prasyarat faktor kompetensi Spencer tersebut akan ditentukan faktor mana saja yang termasuk core factor dan secondary factor dari setiap jabatan. Penentuan core factor dan secondary factor untuk setiap faktor kompetensi Spencer akan berbeda-beda di setiap jabatan. Faktor yang menjadi core factor di jabatan A bisa jadi akan menjadi secondary factor di posisi jabatan lainnya. Selain mengklasifikasikan kategori core factor dan secondary factor, juga ditentukan besaran bobot dari setiap faktor tersebut.

\section{HASIL DAN PEMBAHASAN}

Studi kasus yang digunakan pada penelitian ini yaitu seleksi rekrutmen pegawai untuk menduduki jabatan Marketing Director pada salah satu perusahaan penyedia layanan internet di Indonesia. Untuk setiap faktor kompetensi Spencer yang diprasyaratkan, posisi Marketing Director harus memenuhi faktor kompetensi dengan karakteristik tiap faktor kompetensi seperti tersaji pada Tabel 1 .

TABEL I. KARAKTERISTIK FAKTOR KOMPETENSI SPENCER

\begin{tabular}{|c|c|c|c|c|c|}
\hline No & $\begin{array}{c}\text { Faktor } \\
\text { Kompetensi } \\
\text { Spencer } \\
\end{array}$ & Prioritas & $\begin{array}{c}\text { Nilai } \\
\text { Standar }\end{array}$ & Kelompok & Bobot \\
\hline 1 & $\mathrm{ACH}$ & $\mathrm{CF}$ & 5 & \multirow{4}{*}{$\begin{array}{l}\text { Achievement } \\
\text { and Action } \\
\text { (AA) }\end{array}$} & \multirow[t]{4}{*}{$30 \%$} \\
\hline 2 & $\mathrm{CO}$ & $\mathrm{SF}$ & 3 & & \\
\hline 3 & INT & $\mathrm{CF}$ & 4 & & \\
\hline 4 & INFO & $\mathrm{SF}$ & 3 & & \\
\hline 5 & $\mathrm{IU}$ & $\mathrm{CF}$ & 5 & \multirow{2}{*}{$\begin{array}{l}\text { Helping and } \\
\text { Human Service } \\
\text { (HHS) }\end{array}$} & \multirow[t]{2}{*}{$5 \%$} \\
\hline 6 & $\mathrm{CSO}$ & SF & 3 & & \\
\hline 7 & IMP & $\mathrm{CF}$ & 4 & \multirow{3}{*}{$\begin{array}{l}\text { Impact and } \\
\text { Influence } \\
\text { (IMIN) }\end{array}$} & \multirow[t]{3}{*}{$10 \%$} \\
\hline 8 & $\mathrm{OA}$ & SF & 3 & & \\
\hline 9 & $\mathrm{RB}$ & $\mathrm{CF}$ & 4 & & \\
\hline 10 & DEV & $\mathrm{CF}$ & 5 & \multirow{4}{*}{$\begin{array}{l}\text { Managerial } \\
(\mathrm{MNG})\end{array}$} & \multirow[t]{4}{*}{$30 \%$} \\
\hline 11 & DIR & $\mathrm{SF}$ & 3 & & \\
\hline 12 & TW & $\mathrm{CF}$ & 5 & & \\
\hline 13 & $\mathrm{TL}$ & $\mathrm{CF}$ & 4 & & \\
\hline 14 & AT & $\mathrm{SF}$ & 3 & \multirow{3}{*}{$\begin{array}{l}\text { Cognitive } \\
\text { (COG) }\end{array}$} & \multirow[t]{3}{*}{$15 \%$} \\
\hline 15 & $\mathrm{CT}$ & $\mathrm{CF}$ & 4 & & \\
\hline 16 & EXP & $\mathrm{CF}$ & 4 & & \\
\hline 17 & SCT & $\mathrm{SF}$ & 4 & \multirow{4}{*}{$\begin{array}{l}\text { Personal } \\
\text { Effectiveness } \\
\text { (PE) }\end{array}$} & \multirow[t]{4}{*}{$10 \%$} \\
\hline 18 & SCF & $\mathrm{CF}$ & 4 & & \\
\hline 19 & FLX & $\mathrm{SF}$ & 3 & & \\
\hline 20 & $\mathrm{OC}$ & $\mathrm{CF}$ & 5 & & \\
\hline
\end{tabular}

Untuk seluruh kandidat yang layak menduduki jabatan tersebut akan dihitung datanya untuk setiap komponen diatas dengan skala penilaian kinerja 1 hingga 5 yang berarti tidak memuaskan (1), perlu perbaikan (2), memenuhi harapan (3), melebihi harapan (4) dan luar biasa (5). Sebagai contoh terdapat 10 orang kandidat pegawai untuk menduduki posisi jabatan Marketing Director dengan profil penilaian kinerja seperti yang tertera pada Tabel 2. 
TABEL II. TABel 2. Profil Penilaian KinerJa Kandidat

\begin{tabular}{|c|c|c|c|c|c|c|c|c|c|c|c|c|c|c|c|c|c|c|c|c|c|}
\hline \multirow[b]{2}{*}{ No } & \multirow[b]{2}{*}{ Nama } & \multicolumn{4}{|c|}{ AA } & \multicolumn{2}{|c|}{ HHS } & \multicolumn{3}{|c|}{ IMIN } & \multicolumn{4}{|c|}{ MNG } & \multicolumn{3}{|c|}{ COG } & \multicolumn{4}{|c|}{ PE } \\
\hline & & J्ञ & 8 & $\overline{\mathbf{z}}$ & $\begin{array}{l}0 \\
\text { I } \\
\underline{Z}\end{array}$ & $\Xi$ & $\mathscr{Z}$ & $\stackrel{\hat{\Sigma}}{\underline{\Sigma}}$ & ठే & జै & 存 & 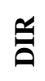 & 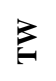 & B & $\overline{4}$ & E & 齐 & $\underbrace{5}_{n}$ & U్d & $\stackrel{\breve{I}}{\vec{I}}$ & ઇ \\
\hline 1 & Kandidat 1 & 4 & 5 & 3 & 2 & 3 & 4 & 3 & 3 & 4 & 4 & 3 & 2 & 4 & 2 & 3 & 4 & 5 & 2 & 3 & 3 \\
\hline 2 & Kandidat 2 & 5 & 3 & 4 & 2 & 4 & 5 & 4 & 4 & 3 & 2 & 4 & 5 & 3 & 3 & 3 & 2 & 4 & 3 & 2 & 2 \\
\hline 3 & Kandidat 3 & 4 & 5 & 5 & 5 & 3 & 2 & 3 & 4 & 3 & 3 & 4 & 2 & 2 & 3 & 4 & 4 & 3 & 3 & 4 & 4 \\
\hline 4 & Kandidat & 3 & 4 & 4 & 5 & 5 & 3 & 4 & 4 & 2 & 3 & 2 & 2 & 2 & 4 & 3 & 4 & 4 & 3 & 3 & 3 \\
\hline 5 & Kandidat 5 & 4 & 3 & 3 & 5 & 5 & 5 & 4 & 3 & 2 & 3 & 4 & 5 & 4 & 3 & 4 & 4 & 3 & 3 & 4 & 4 \\
\hline 6 & Kandida & 4 & 2 & 4 & 5 & 3 & 4 & 3 & 3 & 4 & 4 & 5 & 5 & 4 & 4 & 2 & 4 & 3 & 4 & 3 & 3 \\
\hline 7 & Kandidat 7 & 5 & 4 & 5 & 3 & 3 & 4 & 4 & 3 & 4 & 4 & 5 & 4 & 4 & 5 & 3 & 4 & 3 & 3 & 4 & 3 \\
\hline 8 & Kandidat 8 & 4 & 3 & 5 & 4 & 3 & 4 & 2 & 2 & 4 & 5 & 3 & 4 & 3 & 3 & 4 & 4 & 5 & 5 & 3 & 3 \\
\hline 9 & Kandidat 9 & 2 & 4 & 5 & 4 & 3 & 3 & 4 & 4 & 5 & 5 & 3 & 3 & 4 & 4 & 4 & 2 & 2 & 4 & 4 & 4 \\
\hline 10 & Kandidat 10 & 3 & 4 & 5 & 3 & 2 & 4 & 3 & 4 & 4 & 3 & 4 & 5 & 4 & 4 & 4 & 3 & 3 & 4 & 3 & 4 \\
\hline
\end{tabular}

Selanjutnya untuk setiap data yang ada di Tabel 2 dilakukan perhitungan pencocokan dengan nilai standar yang diinginkan perusahaan. Pencocokan ini berguna untuk mendapatkan nilai selisih antara profil nilai kandidat dengan profil nilai standar. Hasil gap (selisih) dihitung menggunakan rumus persamaan (1) dengan hasil seperti yang tertera di Tabel 3 .

Gap $=$ Profil Nilai Kandidat - Profil Nilai Standar

TABEL III. NILAI GAP KANDIDAT

\begin{tabular}{|c|c|c|c|c|c|c|c|c|c|c|c|c|c|c|c|c|c|c|c|c|c|}
\hline \multirow[b]{2}{*}{ No } & \multirow[b]{2}{*}{ Nama } & \multicolumn{4}{|c|}{$\mathbf{A A}$} & \multicolumn{2}{|c|}{ HHS } & \multicolumn{3}{|c|}{ IMIN } & \multicolumn{4}{|c|}{ MNG } & \multicolumn{3}{|c|}{ COG } & \multicolumn{4}{|c|}{ PE } \\
\hline & & 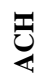 & ○ & 写 & $\begin{array}{l}0 \\
\text { 厌 } \\
\underline{Z}\end{array}$ & $\unrhd$ & రి & $\hat{\sum}$ & $\overleftarrow{0}$ & $\ddot{a}$ & 空 & 光 & 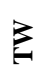 & 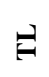 & 自 & 它 & 齐 & 包 & 点 & $\frac{X}{\mid c}$ & ๖ \\
\hline 1 & Kandidat 1 & -1 & 2 & -1 & -1 & -2 & 1 & -1 & 0 & 0 & -1 & 0 & -3 & 0 & -1 & -1 & 0 & 1 & -2 & 0 & -2 \\
\hline 2 & Kandidat 2 & 0 & 0 & 0 & -1 & -1 & 2 & 0 & 1 & -1 & -3 & 1 & 0 & -1 & 0 & -1 & -2 & 0 & -1 & -1 & -3 \\
\hline 3 & Kandidat 3 & -1 & 2 & 1 & 2 & -2 & -1 & -1 & 1 & -1 & -2 & 1 & -3 & -2 & 0 & 0 & 0 & -1 & -1 & 1 & -1 \\
\hline 4 & Kandidat 4 & -2 & 1 & 0 & 2 & 0 & 0 & 0 & 1 & -2 & -2 & -1 & -3 & -2 & 1 & -1 & 0 & 0 & -1 & 0 & -2 \\
\hline 5 & Kandidat 5 & -1 & 0 & -1 & 2 & 0 & 2 & 0 & 0 & -2 & -2 & 1 & 0 & 0 & 0 & 0 & 0 & -1 & -1 & 1 & -1 \\
\hline 6 & Kandidat 6 & -1 & -1 & 0 & 2 & -2 & 1 & -1 & 0 & 0 & -1 & 2 & 0 & 0 & 1 & -2 & 0 & -1 & 0 & 0 & -2 \\
\hline 7 & Kandidat 7 & 0 & 1 & 1 & 0 & -2 & 1 & 0 & 0 & 0 & -1 & 2 & -1 & 0 & 2 & -1 & 0 & -1 & -1 & 1 & -2 \\
\hline 8 & Kandidat 8 & -1 & 0 & 1 & 1 & -2 & 1 & -2 & -1 & 0 & 0 & 0 & -1 & -1 & 0 & 0 & 0 & 1 & 1 & 0 & -2 \\
\hline 9 & Kandidat 9 & -3 & 1 & 1 & 1 & -2 & 0 & 0 & 1 & 1 & 0 & 0 & -2 & 0 & 1 & 0 & -2 & -2 & 0 & 1 & -1 \\
\hline 10 & Kandidat 10 & -2 & 1 & 1 & 0 & -3 & 1 & -1 & 1 & 0 & -2 & 1 & 0 & 0 & 1 & 0 & -1 & -1 & 0 & 0 & -1 \\
\hline
\end{tabular}

Setelah didapatkan nilai gap antara profil nilai kandidat terhadap profil nilai standar, dilakukan konversi nilai gap tersebut terhadap bobot nilai gap dengan ketentuan sesuai dengan tabel 4.
Sehingga data nilai kandidat yang terdapat di Tabel 3, setelah dikonversi sesuai dengan ketentuan yang ada di Tabel 4, bobot nilai gap untuk setiap kandidat seperti yang tertera pada Tabel 5.

TABEL IV. KETENTUAN BOBOT NILAI GAP

\begin{tabular}{|c|c|l|}
\hline Selisih & Bobot Nilai & \multicolumn{1}{c|}{ Keterangan } \\
\hline 0 & 5 & Kompetensi individu sesuai dengan yang dibutuhkan \\
\hline 1 & 4.5 & Kompetensi individu kelebihan 1 level \\
\hline-1 & 4 & Kompetensi individu kekurangan 1 level \\
\hline 2 & 3.5 & Kompetensi individu kelebihan 2 level \\
\hline-2 & 3 & Kompetensi individu kekurangan 2 level \\
\hline 3 & 2.5 & Kompetensi individu kelebihan 3 level \\
\hline-3 & 2 & Kompetensi individu kekurangan 3 level \\
\hline 4 & 1.5 & Kompetensi individu kelebihan 4 level \\
\hline-4 & 1 & Kompetensi individu kekurangan 4 level \\
\hline
\end{tabular}

TABEL V. HASIL KONVERSI NILAI GAP KANDIDAT KE BOBOT NILAI GAP

\begin{tabular}{|c|c|c|c|c|c|c|c|c|c|c|c|c|c|c|c|c|c|c|c|c|c|}
\hline \multirow[b]{2}{*}{ No } & \multirow[b]{2}{*}{ Nama } & \multicolumn{4}{|c|}{ AA } & \multicolumn{2}{|c|}{ HHS } & \multicolumn{3}{|c|}{ IMIN } & \multicolumn{4}{|c|}{ MNG } & \multicolumn{3}{|c|}{ COG } & \multicolumn{4}{|c|}{ PE } \\
\hline & & 苞 & ن & $\overline{\mathbf{z}}$ & 号 & 己 & ర్ & $\hat{\xi}$ & $\overleftarrow{0}$ & $\hat{\simeq}$ & 空 & $\stackrel{a}{0}$ & 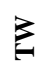 & H & 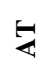 & ย & 斑 & ț & 记 & II & ర \\
\hline 1 & $\begin{array}{l}\text { Kandidat } \\
1\end{array}$ & 4 & 3,5 & 4 & 4 & 3 & 4,5 & 4 & 5 & 5 & 4 & 5 & 2 & 5 & 4 & 4 & 5 & 4,5 & 3 & 5 & 3 \\
\hline 2 & $\begin{array}{l}\text { Kandidat } \\
2\end{array}$ & 5 & 5 & 5 & 4 & 4 & 3,5 & 5 & 4,5 & 4 & 2 & 4,5 & 5 & 4 & 5 & 4 & 3 & 5 & 4 & 4 & 2 \\
\hline 3 & Kandidat & 4 & 3,5 & 4,5 & 3,5 & 3 & 4 & 4 & 4,5 & 4 & 3 & 4,5 & 2 & 3 & 5 & 5 & 5 & 4 & 4 & 4,5 & 4 \\
\hline
\end{tabular}




\begin{tabular}{|l|l|l|l|l|l|l|l|l|l|l|l|l|l|l|l|l|l|l|l|l|l|}
\hline & 3 & & & & & & & & & & & & & & & & & & & & \\
\hline 4 & $\begin{array}{l}\text { Kandidat } \\
4\end{array}$ & 3 & 4,5 & 5 & 3,5 & 5 & 5 & 5 & 4,5 & 3 & 3 & 4 & 2 & 3 & 4,5 & 4 & 5 & 5 & 4 & 5 & 3 \\
\hline 5 & $\begin{array}{l}\text { Kandidat } \\
5\end{array}$ & 4 & 5 & 4 & 3,5 & 5 & 3,5 & 5 & 5 & 3 & 3 & 4,5 & 5 & 5 & 5 & 5 & 5 & 4 & 4 & 4,5 & 4 \\
\hline 6 & $\begin{array}{l}\text { Kandidat } \\
6\end{array}$ & 4 & 4 & 5 & 3,5 & 3 & 4,5 & 4 & 5 & 5 & 4 & 3,5 & 5 & 5 & 4,5 & 3 & 5 & 4 & 5 & 5 & 3 \\
\hline 7 & $\begin{array}{l}\text { Kandidat } \\
7\end{array}$ & 5 & 4,5 & 4,5 & 5 & 3 & 4,5 & 5 & 5 & 5 & 4 & 3,5 & 4 & 5 & 3,5 & 4 & 5 & 4 & 4 & 4,5 & 3 \\
\hline 8 & $\begin{array}{l}\text { Kandidat } \\
8\end{array}$ & 4 & 5 & 4,5 & 4,5 & 3 & 4,5 & 3 & 4 & 5 & 5 & 5 & 4 & 4 & 5 & 5 & 5 & 4,5 & 4,5 & 5 & 3 \\
\hline 9 & $\begin{array}{l}\text { Kandidat } \\
9\end{array}$ & 2 & 4,5 & 4,5 & 4,5 & 3 & 5 & 5 & 4,5 & 4,5 & 5 & 5 & 3 & 5 & 4,5 & 5 & 3 & 3 & 5 & 4,5 & 4 \\
\hline 10 & $\begin{array}{l}\text { Kandidat } \\
10\end{array}$ & 3 & 4,5 & 4,5 & 5 & 2 & 4,5 & 4 & 4,5 & 5 & 3 & 4,5 & 5 & 5 & 4,5 & 5 & 4 & 4 & 5 & 5 & 4 \\
\hline
\end{tabular}

Selanjutnya dilakukan perhitungan nilai akhir dari tiap kandidat dengan memperhitungkan komponen core factor dan secondary factor sebagai berikut :

$$
N C F=\frac{\sum N C}{\sum I C}
$$

dimana

$\mathrm{NCF}=$ Nilai rata-rata core factor

$\mathrm{NC}=$ Jumlah total nilai core factor

IC $=$ Jumlah item core factor

$$
N S F=\frac{\sum N S}{\sum I S}
$$

dimana

$\mathrm{NSF}=$ Nilai rata-rata secondary factor

NS = Jumlah total nilai secondary factor

IS = Jumlah item secondary factor

Sebagai contoh, akan dilakukan perhitungan nilai akhir untuk kandidat pegawai atas nama Taufik Hidayat. Nilai core factor dan secondary factor untuk kelompok faktor kompetensi Achievement dan Action (AA) adalah sebagai berikut :

NCF kompetensi kelompok $A A=\frac{4+4}{2}=4$

NSF kompetensi kelompok $A A=\frac{3,5+4}{2}=3,75$

Rumus perhitungan diatas dilakukan berulang untuk faktor kompetensi Helping and Human Service (HHS),

Impact and Influence (IMIN), Managerial (MNG), Cognitive (COG) dan Personal Effectiveness (PE). Selanjutnya dilakukan perhitungan nilai total untuk setiap kelompok faktor kompetensi dari setiap kandidat yang didapat dari persamaan (4)

$$
\text { Nilai total }(\mathrm{NT})=60 \% \mathrm{NCF}+40 \% \mathrm{NSF}
$$

Nilai total yang didapat oleh setiap kandidat pegawai tertera pada Tabel 6.

Setelah didapatkan nilai total dari setiap kandidat, daftar kandidat pegawai akan diurutkan berdasarkan besaran bobot/pengaruh setiap kelompok faktor kompetensi yang diprasyaratkan untuk jabatan Marketing Director sesuai persamaan (5) sebagai berikut :

Nilai total faktor kompetensi $=\sum_{i=1}^{i=6} b_{i=b o t} * N T_{i}$ sehingga didapatkan hasil akhir seperti yang tercantum pada Tabel 7.

TABEL VI. NILAI TOTAL PER KELOMPOK FAKTOR KOMPETENSI SETIAP KANDIDAT

\begin{tabular}{|l|l|c|c|c|c|c|c|}
\hline \multirow{2}{*}{ No } & \multirow{2}{*}{ Nama } & \multicolumn{6}{|c|}{ Kelompok Faktor Kompetensi Spencer } \\
\cline { 3 - 8 } & & AA & HHS & IMIN & MNG & COG & PE \\
\hline 1 & $\begin{array}{l}\text { Kandidat } \\
1\end{array}$ & 3,9 & 3,6 & 4,7 & 4,2 & 4,3 & 3,7 \\
\hline 2 & $\begin{array}{l}\text { Kandidat } \\
2\end{array}$ & 4,8 & 3,8 & 4,5 & 4 & 4,1 & 3,6 \\
\hline 3 & $\begin{array}{l}\text { Kandidat } \\
3\end{array}$ & 3,95 & 3,4 & 4,2 & 3,4 & 5 & 4,1 \\
\hline 4 & $\begin{array}{l}\text { Kandidat } \\
4\end{array}$ & 4 & 5 & 4,2 & 3,2 & 4,5 & 4,1 \\
\hline 5 & $\begin{array}{l}\text { Kandidat } \\
5\end{array}$ & 4,1 & 4,4 & 4,4 & 4,4 & 5 & 4,1 \\
\hline 6 & $\begin{array}{l}\text { Kandidat } \\
6\end{array}$ & 4,2 & 3,6 & 4,7 & 4,2 & 4,2 & 4,2 \\
\hline 7 & $\begin{array}{l}\text { Kandidat } \\
7\end{array}$ & 4,75 & 3,6 & 5 & 4 & 4,1 & 3,8 \\
\hline 8 & $\begin{array}{l}\text { Kandidat } \\
8\end{array}$ & 4,45 & 3,6 & 4 & 4,6 & 5 & 4,15 \\
\hline 9 & $\begin{array}{l}\text { Kandidat } \\
9\end{array}$ & 3,75 & 3,8 & 4,65 & 4,6 & 4,2 & 4,2 \\
\hline 10 & $\begin{array}{l}\text { Kandidat } \\
10\end{array}$ & 4,15 & 3 & 4,5 & 4,4 & 4,5 & 4,5 \\
\hline
\end{tabular}

TABEL VII. NILAI TOTAL SEMUA FAKTOR KOMPETENSI KANDIDAT PEGAWAI

\begin{tabular}{|l|l|c|}
\hline No & Nama & Nilai Total Semua Faktor Kompetensi \\
\hline 1 & Kandidat 1 & 4,10 \\
\hline 2 & Kandidat 2 & 4,26 \\
\hline 3 & Kandidat 3 & 3,96 \\
\hline 4 & Kandidat 4 & 3,92 \\
\hline 5 & Kandidat 5 & 4,37 \\
\hline 6 & Kandidat 6 & 4,22 \\
\hline 7 & Kandidat 7 & 4,30 \\
\hline 8 & Kandidat 8 & 4,46 \\
\hline 9 & Kandidat 9 & 4,21 \\
\hline 10 & Kandidat 10 & 4,29 \\
\hline
\end{tabular}

Berdasarkan data yang tersaji di Tabel 7 maka kandidat pegawai yang layak untuk menduduki jabatan Marketing Director adalah Kandidat 8 dengan nilai faktor kompetensi Spencer sebesar 4,46 poin.

\section{KESIMPULAN}

Kombinasi faktor kompetensi Spencer dan metode Profile Matching dapat digunakan sebagai dasar seleksi rekrutmen pegawai untuk menduduki jabatan. Dimana tiap jabatan harus didefinisikan terlebih dahulu kompetensi apa 
saja yang harus dipenuhi untuk menduduki jabatan tersebut berdasarkan faktor kompetensi Spencer. Nilai dari tiap faktor kompetensi Spencer yang harus dipenuhi inilah yang menjadi profil nilai standar suatu jabatan. Nilai yang dimiliki oleh setiap kandidat akan menjadi profil nilai kandidat. Pada kasus seleksi rekrutmen pegawai untuk menduduki posisi jabatan Marketing Director, pegawai dengan kode Kandidat 8 merupakan kandidat terkuat dengan perolehan nilai faktor kompetensi Spencer sebesar 4,46 poin.

\section{REFERENSI}

[1] J. S. Toyib, "Pengaruh Sumber Daya Perusahaan dan Orientasi Wirausaha Terhadap Kinerja Usaha Kecil dan Menengah," DeReMa (Development Res. Manag. J. Manaj., vol. 12, no. 2, pp. 243-255, Sep. 2017, doi: 10.19166/derema.v12i2.411.

[2] D. Iskandar, "Strategi Peningkatan Kinerja Perusahaan Melalui Pengelolaan Sumber Daya Manusia dan Kepuasan Kerja dan Dampaknya Terhadap Produktivitas Karyawan," J. JIBEKA, vol. 12, no. 1, pp. 23-31, 2018, Accessed: Jun. 09, 2021. [Online]. Available: https://jurnal.stie.asia.ac.id/index.php/jibeka/article/view/8/5.

[3] O. Onsardi, "Manajemen Sumber Daya Manusia," in MSDM Internasional, 2020, pp. 1-51.

[4] T. Hendra and V. Hafizah, "Pengaruh Analisa Jabatan Terhadap Kinerja Pegawai Negeri Sipil Pada Dinas Kesehatan Kota Pekanbaru," Eko dan Bisnis Riau Econ. Bus. Rev., vol. 11, no. 2, pp. 179-189, Jul. 2020, Accessed: Jun. 09, 2021. [Online]. Available: https://ekobis.stieriau-akbar.ac.id/index.php/Ekobis/article/view/270.

[5] M. F. Arismunandar and H. Khair, "Pengaruh Kompensasi, Analisis Jabatan dan Pola Pengembangan Karir Terhadap Kinerja Karyawan," Maneggio J. Ilm. Magister Manaj., vol. 3, no. 2, pp. 273-282, Oct. 2020, doi: 10.30596/maneggio.v3i2.5129.

[6] F. Filinia, "Kajian Uraian Pekerjaan dan Pemetaan Kompetensi : Studi Kasus pada Perusahaan Pengembang Properti di Surabaya," $J$. Perilaku dan Strateg. Bisnis, vol. 8, no. 2, pp. 108-118, Aug. 2020, doi: 10.26486/jpsb.v8i2.1186.

[7] E. Wahyuni, B. Arief, and N. Anjeli, "Pengaruh Kompetensi dan Promosi Jabatan Terhadap Prestasi Kerja pada PT Bank BPTPN Tbk di Medan," Accumulated J., vol. 2, no. 2, pp. 134-145, Sep. 2020 , Accessed: Jun. 09, 2021. [Online]. Available: http://ejournal.potensi-

utama.ac.id/ojs/index.php/Accumulated/article/view/981.

[8] D. Winarso and E. Arribe, "Seleksi Pegawai dan Dosen UMRI Berbasis E-Recruitment Menggunakan Metode K-Nearest Neighbor," Digit. Zo. J. Teknol. Inf. dan Komun., vol. 8, no. 2, pp. 71-80, Nov. 2017, doi: 10.31849/digitalzone.v8i2.631.

[9] A. Astofa, "Sistem Seleksi Penerimaan Karyawan Dengan Menggunakan Metode Simple Additive Weighting (SAW) Studi Kasus: PT. Raja Kapal," in Prosiding Seminar Nasional Informatika dan Sistem Informasi, 2020, pp. 691-697.

[10] Y. Siagian, "Seleksi Penerimaan Karyawan Baru Menggunakan
Metode TOPSIS," J. Mantik Penusa, vol. 2, no. 1, pp. 65-70, 2018, Accessed: Jun. 10, 2021. [Online]. Available: http://www.ejurnal.pelitanusantara.ac.id/index.php/mantik/article/view/332/218.

[11] A. Wanto and E. Kurniawan, "Seleksi Penerimaan Asisten LAboratorium Menggunakan Algoritma AHP pada AMIK-STIKOM Tunas Bangsa Pematangsiantar," JIKO (Jurnal Inform. dan Komputer), vol. 3, no. 1, pp. 11-18, Feb. 2018, doi: 10.26798/jiko.2018.v3i1.106

[12] M. F. Rozi, E. Santoso, and M. T. Furqon, "Sistem Pendukung Keputusan Penerimaan Pegawai Baru menggunakan Metode AHP dan TOPSIS," J. Pengemb. Teknol. Inf. dan Ilmu Komput., vol. 3, no. 9, pp. 8361-8366, 2019, Accessed: Jun. 10, 2021. [Online]. Available: ptiik/article/view/6154/2962.

[13] K. Khairul and S. Suherman, "View of Seleksi Pegawai Kontrak Menjadi Pegawai Tetap Dengan Metode Profile Matching," IT J. Res. Dev., vol. 2, no. 2, pp. 68-77, 2018, Accessed: Jun. 09, 2021. [Online]. Available: https://journal.uir.ac.id/index.php/ITJRD/article/view/1362/899.

[14] D. A. Kristiyanti, "Sistem Pendukung Keputusan Seleksi Karyawan Untuk Jabatan Tertentu Dengan Pendekatan Analisa Gap Profile Matching," Paradig. - J. Komput. dan Inform., vol. 19, no. 1, pp. 2029, Apr. 2017, doi: 10.31294/P.V19I1.1502.

[15] A. A. M. D. Wijayanthi, "Penerapan Kompetensi Spencer Pada Aparatur Sipil Negara," J. Manaj. Bisnis, vol. 16, no. 4, pp. 75-86, Oct. 2019, doi: 10.38043/jmb.v16i4.2252.

[16] H. Amar and Z. Fikri, "Pengaruh Kompetensi dan Perilaku Kerja Terhadap Kinerja Pemeriksa di Inspektorat Kabupaten Bangka," KEMUDI J. Ilmu Pemerintah., vol. 4, no. 2, pp. 275-291, Apr. 2020, doi: 10.31629/kemudi.

[17] R. Sri Sedjati, A. Qodir, and A. M. Reksiana, "Pengaruh Kompetensi dan Motivasi Kerja Terhadap Kinerja Pegawai pada Bank BJB Cabang Cirebon," J. Ekon. Manaj., vol. 14, no. 2, pp. 309-319, 2019, Accessed: Jun. 10, 2021. [Online]. Available: https://oaj.stiecirebon.ac.id/index.php/jem/article/view/54. 